Article

\title{
Condition Monitoring System and Faults Detection for Impedance Bonds from Railway Infrastructure
}

\author{
Mihai Andrusca ${ }^{1, *}{ }^{\mathbb{C}}$, Maricel Adam ${ }^{1}$, Alin Dragomir ${ }^{1}$, Eduard Lunca ${ }^{1}$, \\ Ramakrishna Seeram $^{2}$ (D) and Octavian Postolache ${ }^{3}$ \\ 1 Power Engineering Department, Gheorghe Asachi Technical University of Iasi, Bd. Dimitrie Mangeron \\ nr. 67, 700050 Iaşi, Romania; adamm@tuiasi.ro (M.A.); alin.dragomir@tuiasi.ro (A.D.); elunca@tuiasi.ro (E.L.) \\ 2 Mechanical Engineering Department, National University of Singapore, 21 Lower Kent Ridge Rd, \\ Singapore 119077, Singapore; seeram@nus.edu.sg \\ 3 Instituto Universitário de Lisboa (ISCTE-IUL) and Instituto de Telecomunicações (IT-IUL), \\ Av. das Forças Armadas, 1649-026 Lisbon, Portugal; opostolache@lx.it.pt \\ * Correspondence: mandrusca@tuiasi.ro; Tel.: +40-749-533355
}

Received: 24 July 2020; Accepted: 2 September 2020; Published: 4 September 2020

check for updates

\begin{abstract}
Nowadays, sensors and condition monitoring systems are expanding rapidly and becoming cheaper. This contributes to increasing developments in condition monitoring in railway transport infrastructure. A condition monitoring system that uses an online device and sensors to acquire electrical parameters from railway infrastructure has been developed and applied for fault detection and diagnosis of impedance bonds. The impedance bond condition is monitored in real-time using current and temperature sensors, providing early warning if predefined thresholds are exceeded in terms of currents, imbalance currents, and temperatures. The proposed method and the developed monitoring device have been validated in the railway laboratory to confirm its capability to detect defects. The acquired parameters from impedance bonds are used to extract thermal stresses and technical conditions of this equipment. Experimental results and appropriate data analysis are included in the article.
\end{abstract}

Keywords: return circuit; monitoring device; sensors; diagnosis; thermal stress

\section{Introduction}

Railway transport is one of the main ways to move in the world. An efficient transport system is a fundamental condition for wellbeing and prosperity at national and international levels.

In recent years, there has been a tendency to use railway infrastructure electrical equipment up to their limits, assuming the risk of failure, which leads to power supply interruption of the railway system. Those things lead to undesirable aspects in terms of train circulation (delays, injuries, etc.), with economic and technical losses.

Railway infrastructure generally uses scheduled maintenance activities. This type of maintenance is expensive and time-consuming since the activities have to be performed periodically. However, some failures will occur between the scheduled activities. Thus, the corrective maintenance performed after such an event has high costs. Traditionally, the return circuit (which contains impedance bonds) is monitored visually (manually) by railway maintenance workers. However, human monitoring is a subjective method, which is slow and unsafe for railway infrastructure.

Timely detection and identification of faults in railway infrastructure are very important for the availability, reliability, and safety of the railway system. In order to reduce the failure risk in railway infrastructure, it is necessary to acquire, collect, and process detailed information about the 
technical condition of equipment and, thereby, enable prediction for any damage to the electrical equipment [1-3].

Faults detection and diagnosis is the next step after railway infrastructure condition monitoring. In this sense, some diagnosis methods of railway infrastructure have been proposed in the literature [2-5].

The introduction of monitoring and diagnosis allows passing from corrective maintenance, respectively, maintenance based on predetermined criteria (time), existing in high percentage in the railway infrastructure, to condition-based maintenance, in order to increase the operational safety and the railway traffic, to ensure power supply continuity of the railway, to reduce the duration of non-power supply of the contact line, to minimize system losses, to reduce the risk of failure, to reduce the operating costs, etc.

In [6-8], aspects of condition monitoring in the railway industry are presented, in which the sensors used for monitoring the railway infrastructure are highlighted. Moreover, the authors divide the railway infrastructure into two large components: fixed and movable [6]. The rail tracks, bridges, tunnels, rail track beds, and other infrastructure, are found in the fixed elements. The return circuit and the track circuit are found as part of the other railway infrastructure. On the other hand, the wagon, bogies, axles, brakes, pantographs, etc., are included in the movable components.

Among the electrical equipment from the return circuit and track circuit, which need special attention, are the impedance bonds that are mounted in railway infrastructure $[9,10]$. Its main functionalities are:

- to ensure the return circuit of the electric traction current;

- $\quad$ to separate the signaling current of the track circuit from the traction current;

- to control and to signal the trains circulation;

- to ensure the protection of the installations from the contact line vicinity.

In exploitation, the impedance bond is subjected to thermal, mechanical, electrical, and environmental stresses [11]. To avoid some faults, it is essential to monitor the relevant parameters in their incipient phase, which characterize the technical condition of the impedance bond.

Impedance bond condition monitoring consists of characteristic parameter observation of equipment, to verify its performance through measuring one or more of these parameters (measurements performed with sensors and data processing devices, permanently connected to the equipment). Furthermore, a comparison of measured values with specified ones from the manufacturer, or with previously determined values, are included in condition monitoring [11,12]. Moreover, the introduction of artificial intelligence in faults diagnosis will obtain high accuracy in detecting some problems in the incipient phase to improve the availability and safety of the train operation $[1,13,14]$.

Presently, no reports regarding impedance bond monitoring and diagnosis are presented in the literature; however, some patents close to this field of research [15-19] can be mentioned. Thus, the patent [15] related a system and method for detecting a broken rail and occupied track from a railway vehicle. The authors of [16] have developed an onboard measurement system for railway vehicle wheel flange wear. Tsunashima et al. in [17-19] have developed and implemented an in-service condition monitoring device, which is applicable for long-term condition monitoring of tracks being composed of: a compact device, data collection, and remote data collection via cellular phone. The onboard device was made for track fault detection by measuring the acceleration of bogies.

In previous years, railway infrastructure monitoring has been based more on wireless sensor networks [6-8,20-26]. Thus, in [6-8], the authors present wireless devices and sensors, which can be used in railway infrastructure to assist in decision-making processes for improving maintenance activities through real-time monitoring. In [20], a wireless network technology is presented for railway bridge monitoring from the railway infrastructures. The wireless network collects information (vibration, temperature, material deformation) for knowing the structural health and behavior of 
infrastructure when a train moves over. Moreover, the paper [21] describes the wireless network for monitoring structural monitoring of tunnels.

The aim of [22] is to present an early warning system, based on a wireless network, for railway infrastructure monitoring and environmental security monitoring against natural hazards and intentional threats (earthquakes, fire, explosions, etc.). In [23] are shown aspects of the optimal energy resources allocation method of wireless sensor networks for railway status monitoring. Gao et al. [24,25] presented wireless sensor nodes with the Zigbee protocol, and self-powered for railway condition monitoring.

Thus, in this paper, a condition monitoring system that uses an online device and sensors for acquiring some electrical parameters from railway infrastructure is described. It was developed and applied for faults detection and the diagnosis of impedance bonds. Moreover, for understanding the role of the impedance bond in railway infrastructure, the power supply system from the electric railway traction is presented. Furthermore, aspects of the impedance bond (as a component of the return circuit from railway infrastructure) is presented. The necessity for monitoring and diagnosis of the impedance bond and the parameters, which must be monitored to detect incipient faults, are discussed.

Furthermore, with the condition monitoring system and thermal camera, a thermal analysis of the electrical contacts between the impedance bond and railway tracks (from the return circuit of electric traction) was made. The laboratory experiment consists of the obtained results analyses in different situations that could occur in exploitation. Four cases were analyzed for the connection between impedance bond and railway tracks. These connections were performed through cables made from different materials and with different cross-sections.

\section{Aspects about the Impedance Bond of the Return Circuit from the Power Supply System of Railway Infrastructure}

A power supply system from electric traction represents the assembly of the installations used to transform, transmit, and consume the electrical energy necessary for people and cargo railway transport. The electric traction power systems are of different types, depending on the current-direct current (DC) or alternating current (AC), the voltage, and the frequency of the contact line power supply. Over time, these power supply systems had continuous development depending on the technologies available at the time of their appearance.

The first supply systems from the electric traction used the DC power supply, with the voltage values of $1.5 \mathrm{kV}, 3 \mathrm{kV}$, or $6 \mathrm{kV}$. The next power supply systems used the AC single phase at the voltage value of $15 \mathrm{kV}$ and the frequency $162 / 3 \mathrm{~Hz}$ or $25 \mathrm{~Hz}$, respectively, the systems in the AC single phase at the voltage of $25 \mathrm{kV}$ and the supply system of $2 \times 25 \mathrm{kV}$ with the frequency of $50 \mathrm{~Hz}$. The evolution of the electric traction power systems was due, first, to the necessity of removing some disadvantages of the existing systems [27-29].

Currently, the power systems presented above are used on a smaller or larger scale; the most widespread supply system being the AC single phase at the voltage value of $25 \mathrm{kV}$ and $50 \mathrm{~Hz}$.

The main elements of a power supply system in AC reported in [30-32] are:

- overhead line or underground line to supply the electric traction substations;

- electric traction substations that ensure the reduction of the $\mathrm{AC}$ voltage level to the value required to power supply the contact line, $25 \mathrm{kV}$;

- electrical installations and equipment for supplying the contact line (power supply feeder, return feeder);

- the contact line, built along the railway, is an overhead electrical network that power supplies the consumers (locomotives and electric frames) from the electric traction;

- $\quad$ section post, subsection post for transverse, and longitudinal sectioning of the contact line;

- the railway tracks, which have a dual role, namely: of the track running and of the return conductor for the current to the electric traction substation; 
- consumers (locomotive and electric frame, internal consumers);

- devices for monitoring, diagnosis, remote control, and remote signaling of the power supply system.

An essential element of the power supply system from electric railway traction is the impedance bond from the return circuit, which is the subject of this research.

Figure 1 shows the return circuit of the traction current from the power supply system of electric traction, where the impedance bond can be found.

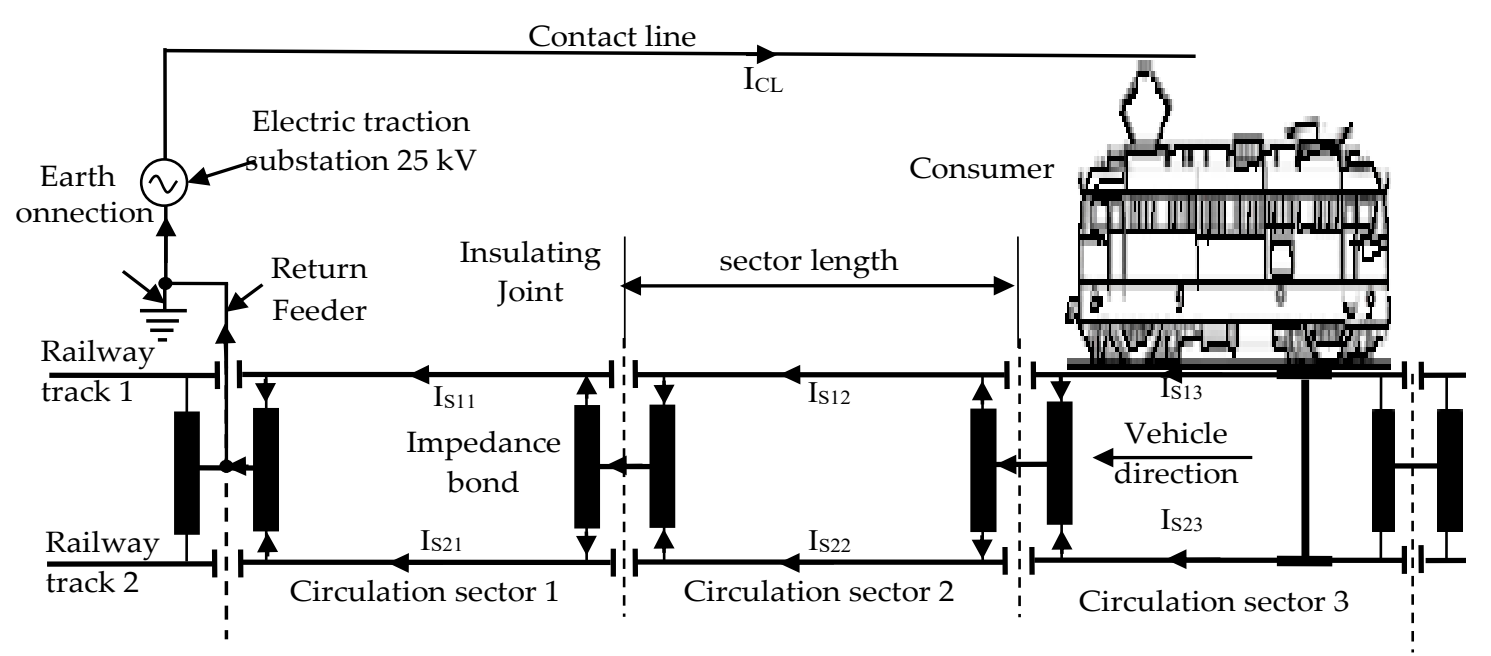

Figure 1. Traction current return circuit from the power supply system of railway infrastructure.

Generally, the return circuit is composed of all conducting paths (railway tracks, impedance bonds, connecting conductors between the railway tracks, and impedance bond, return feeders) that form the return path of the traction current to the power supply substation [32,33].

In Romania, to increase the volume of freight transported, and the safety of the railway traffic, the railway track is divided into certain lengths called circulations (traffic) sectors. Passing the traction current from one sector to another is made through the impedance bond, which ensures the continuity of the current return circuit from the electrical substation.

The impedance bond, besides ensuring the continuity of the return path of the electric traction current, is part of the track circuit, which allows controlling and signaling the running of trains [32,34].

Moreover, another important issue is the large number of impedance bonds found on the power supply system of railway infrastructure to separate this system in circulation sectors of $1.6 \mathrm{~km}$ in length. If the impedance bond is broken, the consumers (locomotives) on that circulation sector are not supplied. This aspect runs to undesirable consequences in terms of the circulation of trains with economic and technical losses.

Essentially, the impedance bond is a transformer that has a ferromagnetic core with a silicon sheet, on which are located two windings. The first winding is for traction current (primary windings and dimensioned at a nominal current of $250 \mathrm{~A}$ ), which has a median socket and the connection terminals, A1-M-A2; the second winding is of the control current (secondary winding) with the terminals B1-B2, Figure 2.

From a constructive point of view, the impedance bonds can be realized in a single (Figure 2a) or double (Figure 2b) structure. In Figure 3 is an image with the impedance bonds that can be found in operation in the simple configuration in cast iron casing (the classic impedance bonds) and in double configuration polyamide or polyester enclosures, reinforced with glass fibers (the modernized impedance bonds) [32,34]. 


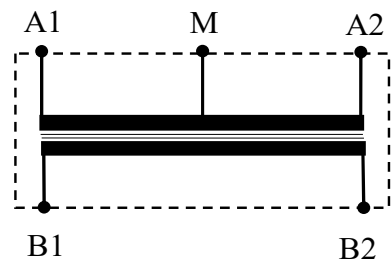

a)

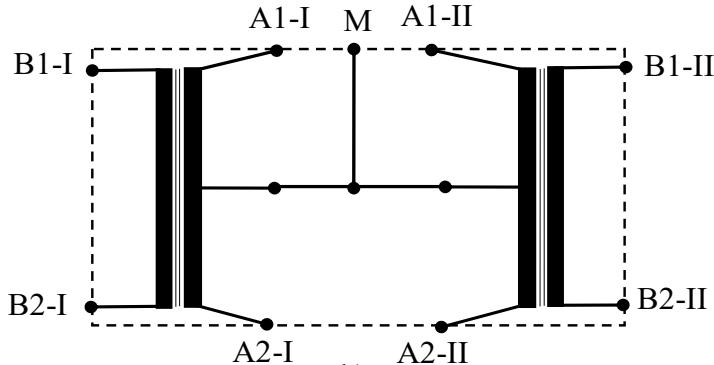

b)

Figure 2. Impedance bond electrical diagram in two constructive variants: (a) simple; (b) double.

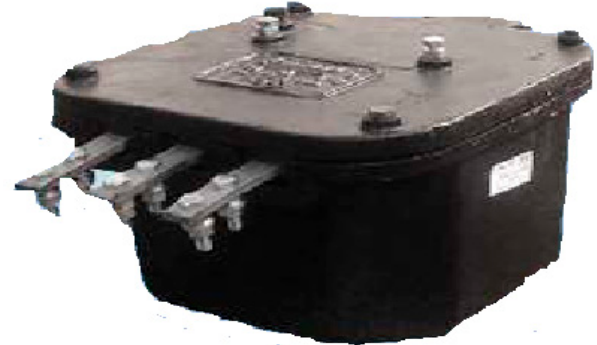

(a)

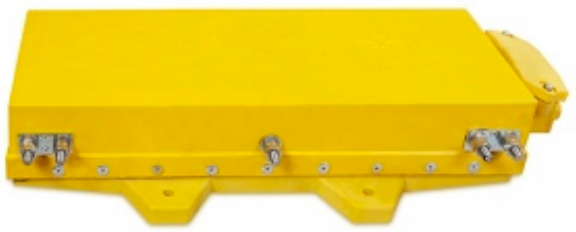

(b)

Figure 3. Image of impedance bonds: (a) simple in cast iron casing; (b) double in a non-metallic housing.

The electrical equipment complexity and diversity, which composes the return circuit, and imposes the need to ensure its proper operation and maintenance to avoid the appearance of abnormal operating regimes.

\section{Condition Monitoring of the Impedance Bonds}

\subsection{Aspects about Monitoring and Possible Faults of the Impedance Bonds}

Monitoring and diagnosis of the electrical equipment technical condition from the supply system of electric traction are starting to be increasingly used due to the development of sensors and transducers, devices for monitoring, and diagnosis, respectively, new possibilities of data transmission acquired. The emergence and development of new technologies allow the development of devices for monitoring and diagnosis that meet the requirements of electric traction [6-8,35].

The necessity to monitor the impedance bonds arose due to their importance in ensuring the return of traction current to the power supply, respectively, the control and signaling of the railway vehicles to achieve the safety and availability of the railway traffic. Thus, the monitoring and diagnosis of the impedance bonds will lead to the detection of incipient faults and reduce the delays in the train circulation.

In this context, aspects regarding the problems/faults are presented, which can appear on impedance bonds from the power supply system of the electric traction and possibilities for monitoring and diagnosis of this kind of equipment.

Thus, during the maintenance activities of the impedance bonds, there were often problems related to the return circuit from electrical traction, such as [32,34]:

- oxidized electrical contacts;

- insufficient tightening of the connection terminals;

- interruption (sometimes lack) of the connecting cables between the impedance bond terminals and the railway track; 
- interruption of the railway track;

- $\quad$ short-circuit in the winding of impedance bond;

- interruption of the track circuit.

To detect the faults from the return circuit and to limit the negative effects, respectively, the reduction of the occurrence number of abnormal situations can be achieved by continuous monitoring and diagnosing the impedance bonds. In Table 1 are given some parameters and techniques to determine the technical condition of the impedance bond. Integrating a larger number of these parameters will allow extracting the real condition of the equipment with more accuracy.

Table 1. Parameters and techniques for monitoring and diagnosing of the impedance bond.

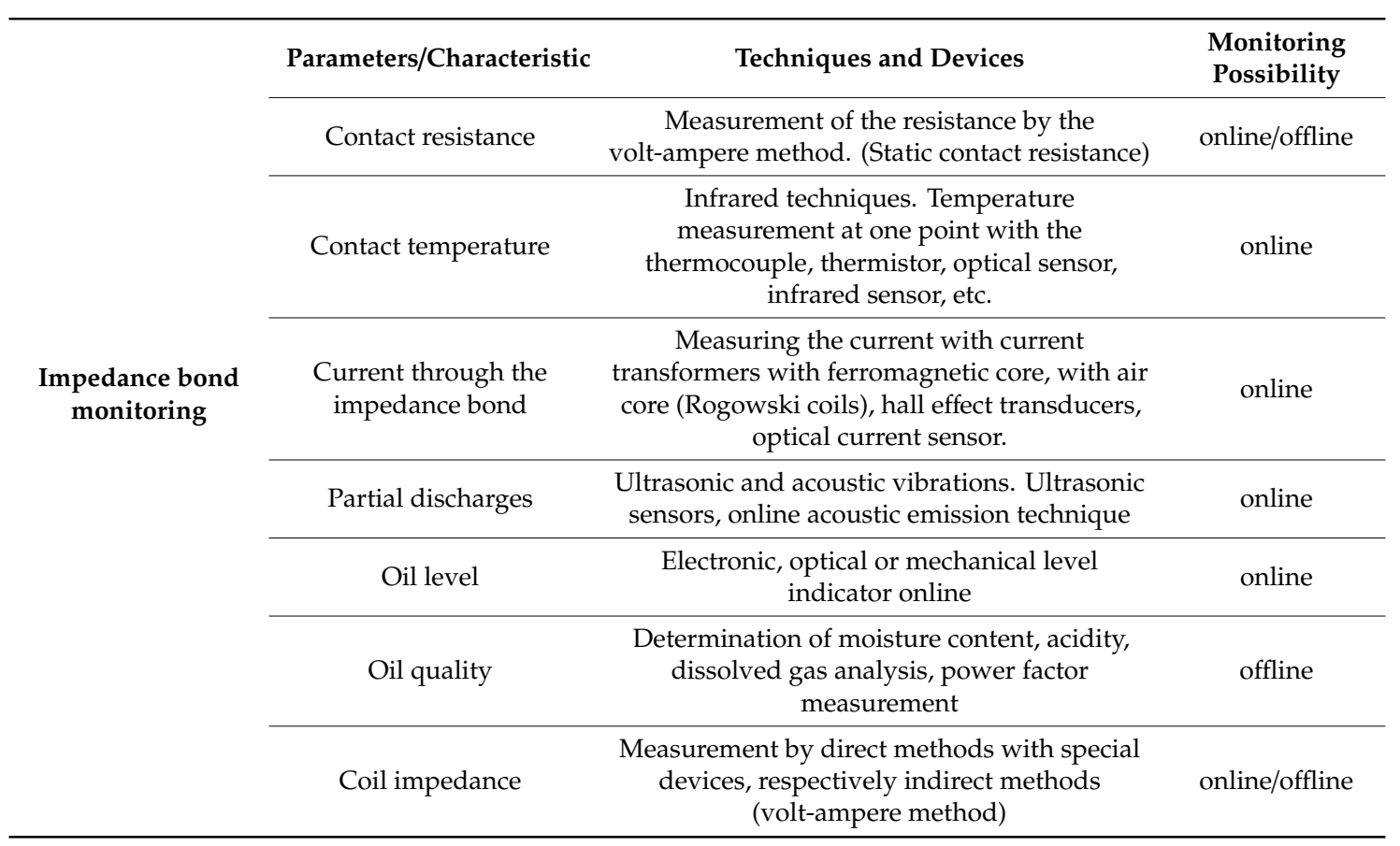

It was found that a multitude of characteristics and parameters must be monitored in order to diagnose the impedance bond technical condition.

Thus, by monitoring the currents through the two primary impedance bond windings, the imbalance current can be easily obtained, which indicates the connection interruption between the impedance bond terminal and one of the railway tracks (at 100\% imbalance). Knowing the temperatures in different areas of the impedance bond (the connection terminals A1, A2, and $\mathrm{M}$, the connection cables, the coil housing, and the environment) allows us to identify the monitored areas status.

In addition, correlating the current passing through the impedance bonds and a higher contact area temperature indicates an increase of connection terminals contact resistance (so, contact state deterioration).

Knowing the coil housing temperature allows the evaluation of the sources of heat from inside coil housing or the cooling conditions. The heat sources are mainly due to the losses from the Joule effect in the impedance bond windings and the terminal connections in the impedance bond housing, or by hysteresis and eddy current losses in the magnetic circuit. A housing temperature increasing at the same current value, correlated with the ambient temperature, may occur due to: the inside contact areas deterioration of the impedance bond; the short turns appearance; magnetic circuit deterioration; low oil level (or lack of it).

In conclusion, monitoring and diagnosis must allow good knowledge of the impedance bonds' technical conditions to retain their behavior in the most varied situations (i.e., temperature in the contact areas, the current imbalance through the two railway tracks, the interruption of the connecting 
conductors between the impedance bond terminals and railway tracks, etc.), and compare it with a database of other impedance bonds of the same type, but exposed under similar conditions. This fact is of great importance because the data obtained by impedance bond monitoring will prevent the occurrence of electrical traction installations malfunctions.

\subsection{Condition Monitoring Device and Sensors Used for Monitoring the Impedance Bonds}

Considering the above presented aspects about the necessity of impedance bond monitoring and diagnosing, for limiting the negative effects, both technical and economic-in the following sections are presented an experimental device that was developed for monitoring and diagnosing an impedance bond in real-time.

The condition monitoring device was designed and realized from the need to monitor the parameters discussed above (currents, temperatures). The device role is to prevent possible faults in the operation of the railway signaling installations on the electrified lines in the traction power system, respectively, the avoidance of the return circuit interruption that will lead to delays in the circulation of the trains, and some technical and economic loses.

The architecture of the device was designed specially to allow acquiring data in real-time and to intervene in case of anomalies appearance [35].

Figure 4 presents the block diagram of the hardware structure for the condition monitoring of the impedance bond.

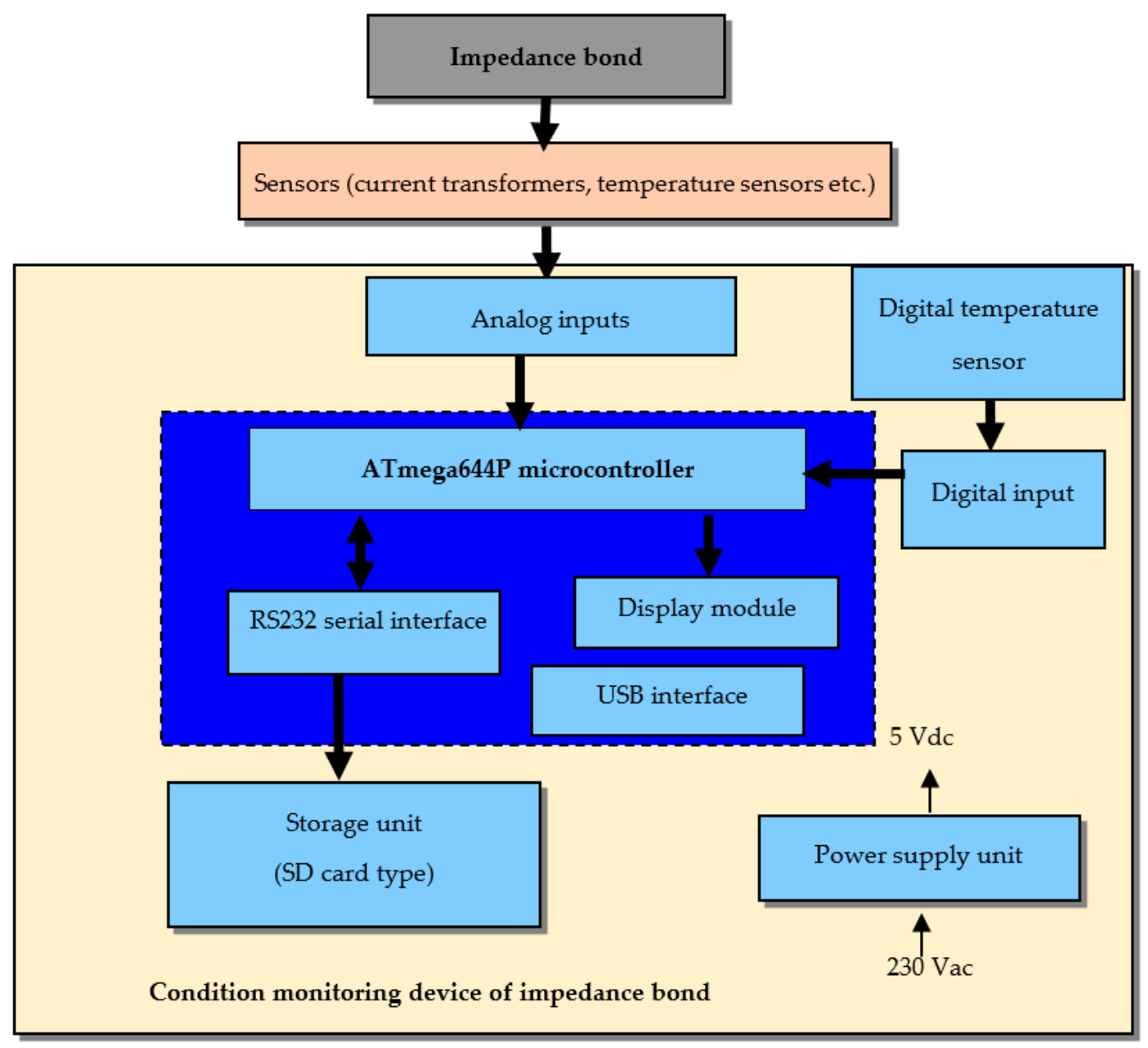

Figure 4. Condition monitoring device block diagram of the impedance bonds. 
The main elements of the condition monitoring device used to acquire and record the parameters on the impedance bond are:

- ATmega644P microcontroller;

- two current transducers based on Hall effect of LEM LTS 6-NP type;

- two current transformers;

- four Negative Temperature Coefficient (NTC) temperature sensors;

- digital temperature sensor of DS18B20 type;

- power supply module of Tracopower TMLM 04105 type;

- communication interfaces with TTL/RS232 converter and TTL/USB converter;

- $\quad$ SD-card module of ROGUE uMMC type for local data storage;

- $2 \times 16$-character liquid crystal display, for monitoring device configuration and data displaying;

- GSM modem.

The electronic part of the impedance bond monitoring and diagnosis device was built around the ATmega644P microcontroller, an 8-bit microcontroller in Reduced Instruction Set Computing (RISC technology), which, by its flexible properties and low cost, offers an ideal solution for many applications in the engineering field.

The microcontroller is characterized by: 10 bit Analog to Digital Converter (ADC); calibrated internal RC oscillator; internal and external interrupt sources; two programmable serial ports USART1, USART2; two serial interfaces; two SPI serial ports.

Figure 5 shows the frontal image of the embedded system. Thus, the connection terminals, the configuration keys of the device, the local display, GSM modem, etc., can be observed. The hardware architecture of the device was designed for specific working conditions to electric traction, being made a compact and robust structure, suitable for insertion in housing that can be mounted on the omega rail, the rail commonly used in switchboards.

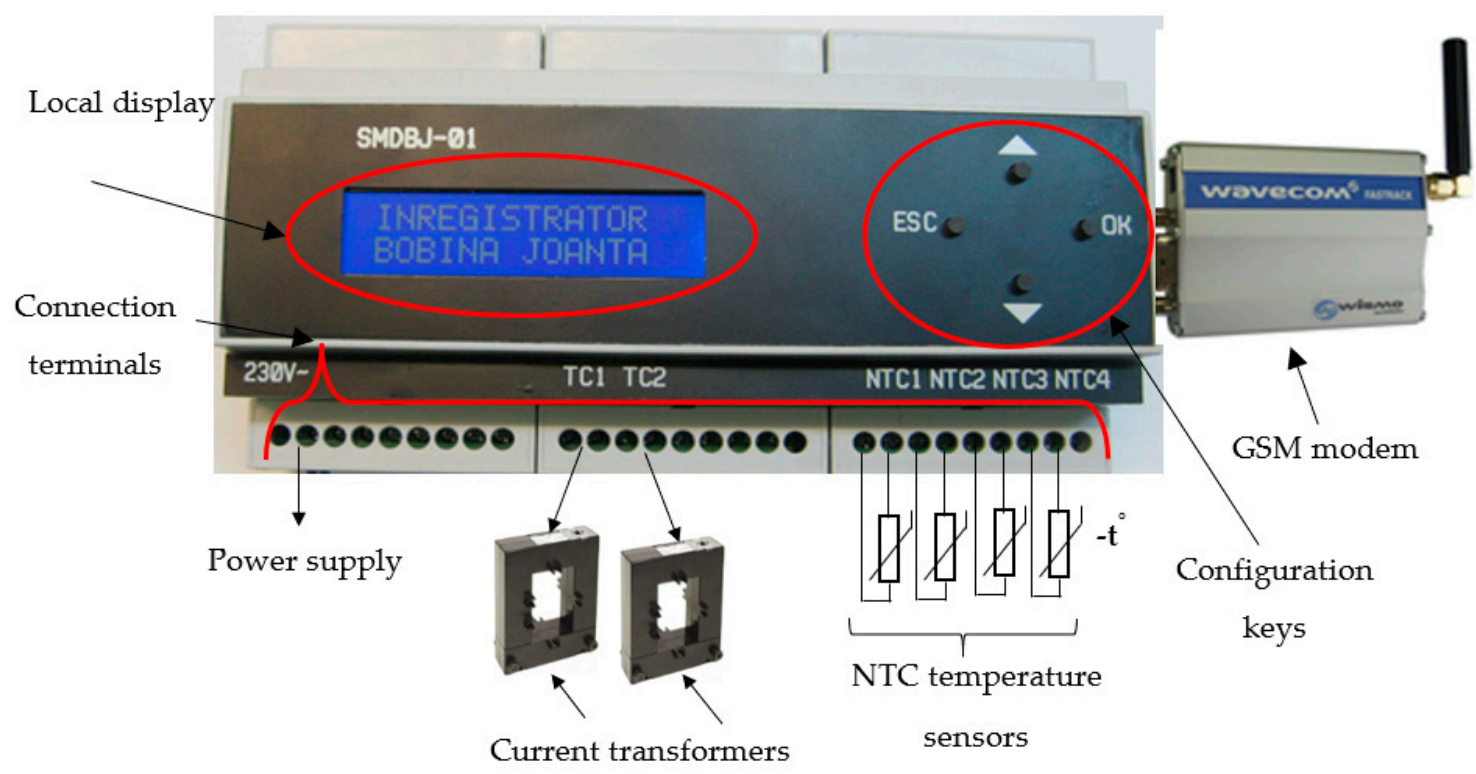

Figure 5. Image with monitoring and diagnosis device of impedance bonds.

Among the characteristics of the device designed and performed:

- $\quad$ direct supply from the operative voltage (230 V AC);

- displaying on LCD the temperatures acquired from each sensor of the impedance bond, as well as the traction current; 
- recording all the parameters on an SD-card;

- $\quad$ sending alarms via a communication interface (GSM) to an operator.

During monitoring of the parameters from the impedance bond, the following data are acquired and stored:

- the traction currents on the two railway tracks;

- the current imbalance between the two railway tracks;

- interrupting a connection cable to one of the railway tracks;

- the temperature on each terminal and the connection ropes;

- the temperature from the impedance bond housing.

The device can be mounted in the relay cabinets at each railway sector, and the connection to the impedance bond is made by installing the temperature transducers on the terminals, respectively, the housing, and the current transformers on the connecting conductors between the railway tracks and impedance bond terminals.

Further, the current transformers characteristics are presented, respectively, the sensors (current and temperature sensors) used for monitoring of the impedance bond parameters.

\subsubsection{Current Transformers}

For measuring the currents through the windings of the impedance bond, a current transformer (inductive type) is used, with the transformation ratio of 250/5 A. Each transformer is specially designed to be mounted in measuring circuits without the need to undo the connections of the connecting conductors between the terminals of the impedance bond and railway tracks. For current measurements, the precision class is 1 , and the apparent power is $1.5 \mathrm{VA}$.

\subsubsection{Current Transducers with Hall Effect}

In order to interface the current transformer for measuring high currents, within the device, two inputs characterize the current transducers. Current transducers (with Hall effect) are placed on the main board of the device. They have a rated current of $6 \mathrm{~A}$ and can measure both direct current and alternating current. In this case, the measurement is $\mathrm{AC}$ and acquires currents from the secondary windings, from the current transformer described above.

The characteristics of LEM LTS 6 transducer at $25^{\circ} \mathrm{C}$ are primary nominal RMS current, $6 \mathrm{~A}\left(\mathrm{I}_{\mathrm{p}}\right)$; primary current, measuring range $0 \ldots \pm 19.2\left(\mathrm{I}_{\mathrm{pn}}\right)$; output voltage (analog) of $2.5 \pm\left(0.625 \times \mathrm{I}_{\mathrm{p}} / \mathrm{I}_{\mathrm{pn}}\right) \mathrm{V}$; sensitivity, $104.16 \mathrm{mV} / \mathrm{A}$; internal measuring resistance, $208.33 \Omega( \pm 0.5 \%)$; accuracy $\mathrm{I}_{\mathrm{pn}}, \pm 0.2 \%$; supply voltage $5 \mathrm{Vdc}$.

\subsubsection{Temperature Sensors}

The temperature sensors used to measure the temperature values on the impedance bond terminals, respectively, on its housing, are of the Negative Temperature Coefficient (NTC) thermistor type. Generally, they are made of metal oxides (manganese, nickel, cobalt, copper, iron, etc.) and have a temperature measurement range of $-75^{\circ} \mathrm{C}$ to $+300{ }^{\circ} \mathrm{C}$, with accuracy $\pm 1 \%$. They are based, as a working principle, on changing the electrical resistance with temperature changes. Among the advantages of this method of measurement, it can be noted that they have a high resolution, slow temperature inertia, high sensitivity. As a disadvantage, it mentions that they are not linear.

The chosen thermistors have nominal values of $10 \mathrm{k} \Omega$ at $25{ }^{\circ} \mathrm{C}$ and are interfaced to the microcontroller via a voltage divider network, which is designed so that the power dissipated on thermistor never exceeds $1 \mathrm{~mW}$ (in reality, this power is even lower). Because of the non-linear response of the thermistors, a look-up table is used to determine the temperature in software. Taking into account the limited ADC accuracy, the estimated error when using the linear interpolation does not exceed $0.7^{\circ} \mathrm{C}$ for the temperature range from $-40{ }^{\circ} \mathrm{C}$ to $140{ }^{\circ} \mathrm{C}$ and approaches $1.6^{\circ} \mathrm{C}$ at the temperature of 
$200{ }^{\circ} \mathrm{C}$. These calculated errors are considered satisfactory for the purpose of the application, but they can further be improved by selecting a finer temperature step in the look-up table, i.e., by storing more $\mathrm{ADC}$ results.

\subsubsection{Digital Temperature Sensors}

The digital temperature sensor is used to acquire the PCB temperature. This sensor type is DS18B20, which is found inside of the device on the mainboard, and it offers temperature readings with a resolution from 9 bits to 12 bits (configurable). It has an alarm function with a non-volatile programmer at the upper and lower trigger points.

The digital temperature sensor communicates with the microcontroller through a 1-Wire bus that, by definition, requires only a single data line (and ground) for communication with the microcontroller. The measuring range is in the interval $\left(-55^{\circ} \mathrm{C} \ldots+125^{\circ} \mathrm{C}\right)$, with an accuracy of $\pm 0.5^{\circ} \mathrm{C}$. The power required for reading, writing, and performing temperature conversions can be obtained from the data line itself, without the need for an external power source.

By using all of these sensors described above, the impedance bond parameters are acquired. These measurements provide valuable information about the impedance bond condition and allow, in most cases, accuracy in checking the presence or absence of anomalies.

The software component is added to the hardware part of the device that involves the proper programming of the microcontroller, respectively reading, processing, and analyzing the acquired data by the hardware components of the device.

For easier microcontroller programming, a connector has been introduced in the electric scheme, which allows In System Programming (ISP). The microcontroller software was designed to acquire the temperatures from the 4 NTC temperature sensors placed on each impedance bond terminal and one for its housing. The currents from each impedance bond semi-winding were acquired from two current transformers. The software was developed to transmit locally on the SD-card the monitored parameters or a local PC, and to display the measured temperatures on LCD.

The microcontroller programming was done in the CodeVisionAVR environment, an ANSI C Compiler for Microchip AVR Microcontrollers. Upload the firmware in microcontroller was made using PonyProg, programming for serial devices.

Acquisition of the impedance bond parameters can be performed in two ways: manually by selecting from the menu data acquisition the "Data acquisition in file $x \times x 1$ " and automatically when exceeding the specified current threshold. The data acquisition period ranges from 1 to $10 \mathrm{~s}$, and acquired data are stored on an internal SD card. They can further be downloaded to a computer or directly transmitted to PC by communication interfaces.

The monitored parameters are recorded on SD card in CSV format, and can be downloaded to the computer for additional analysis. If the predetermined value was exceeded, the device launched an alarm signal indicating that one of the impedance bond parameters had passed into an unacceptable range.

Finally, the device is capable of locally displaying all relevant data, and transmitting several types of alarms through GSM:

- exceeding a minimum/maximum temperature limit for each monitored temperature point;

- exceeding the maximum current allowed by each half impedance bond winding;

- exceeding a maximum allowable imbalance between the currents on each rail;

- detecting the interruption of a connection cable.

The monitoring device was tested and validated according to the internal instructions of the railway laboratory, using a test setup similar to that in Figure 6, at multiple current values. The results are based on repeated measurements, the number is sufficient to give uncertainty. For a test current of $150 \mathrm{~A}$, the estimated expanded uncertainty (stated at the standard uncertainty of measurement 
multiplied by the coverage factor $\mathrm{k}=2$, which, for a normal distribution corresponds to a coverage probability of approximately $95 \%$ ) is $4.94 \%$.

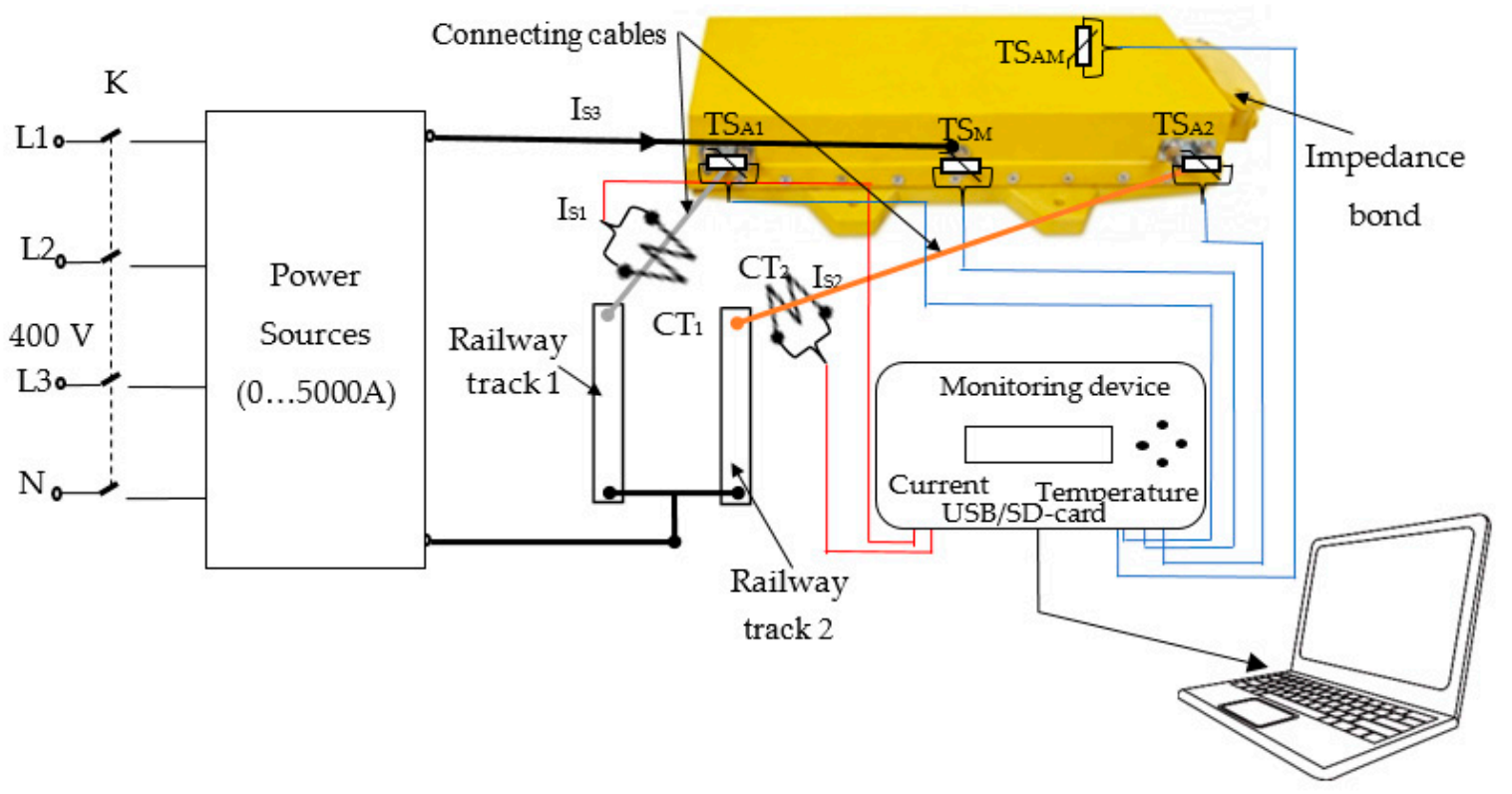

(a)

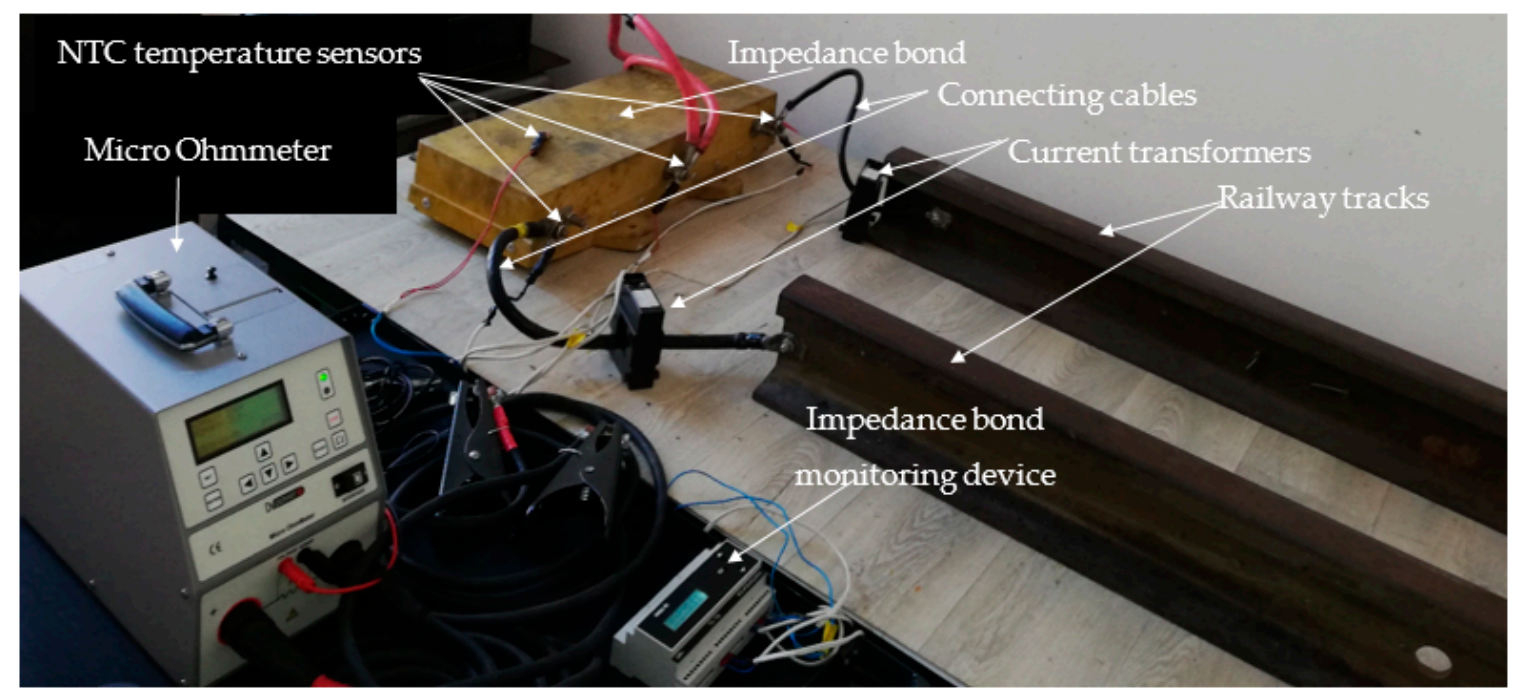

(b)

Figure 6. Experimental installation for condition monitoring of the modernized impedance bond: (a) the block diagram for experimental tests; (b) the image of the experimental installation.

Table 2 gives technical specifications of the impedance bond monitoring and diagnosis device. It can be mounted on each impedance bond existing in the return circuit from electric traction. 
Table 2. Technical specifications of the impedance bond monitoring and diagnosis device.

\begin{tabular}{|c|c|}
\hline \multicolumn{2}{|c|}{ Technical Specifications } \\
\hline Number of current inputs & 2 \\
\hline Current measurement range & $0 \ldots 300 \mathrm{~A}$ \\
\hline Current accuracy & $\pm 3 \%$ \\
\hline Current measurement resolution & $0.1 \mathrm{~A}$ \\
\hline Current transducer on PCB & LEM 6 A type \\
\hline Number of temperature inputs & 5 \\
\hline Temperature measurement range & $-40^{\circ} \mathrm{C} \ldots 250^{\circ} \mathrm{C}$ \\
\hline Temperature measurement resolution & $0.1^{\circ} \mathrm{C}$ \\
\hline Temperature sensor & NTC thermistor type \\
\hline Temperature accuracy & $\pm 2 \%$ \\
\hline Programming mode & ISP connector \\
\hline Communication interface & RS 232, USB, GSM \\
\hline Data recording & PC, SD-card \\
\hline Card type & $\mathrm{SD} / \mathrm{miniSD} / \mathrm{microSD}$ \\
\hline SD-card memory & $8 \mathrm{MB} \ldots 32 \mathrm{~GB}$ \\
\hline Display & LCD $16 \times 2$ characters, lighting \\
\hline Operating temperature & $-40^{\circ} \mathrm{C} \ldots+85^{\circ} \mathrm{C}$ \\
\hline Power supply & $90 \ldots 264 \mathrm{Vca}$ \\
\hline Exterior dimensions & $90 \times 155 \times 60 \mathrm{~mm}$ \\
\hline
\end{tabular}

\section{Results}

\subsection{Experimental Installation for Testing of the Impedance Bond with Condition Monitoring Device and} Faults Detection

After design, realization, testing, and validation of the monitoring device in laboratory conditions, a thermal analysis of the return circuit from electric traction was performed. Moreover, in order to establish the technical condition of the impedance bond, faults that may occur in exploitation were highlighted.

The thermal stresses of the return circuit from the electric railway traction are produced by the electrocaloric effect of the current flowing through it. Thus, by monitoring this component of electric traction, it is possible to evaluate the thermal stresses.

The analyzed parts of the return circuit are the contacts between the impedance bond and railway tracks from the return circuit of electric traction, where the connection is performed through cables made from different materials and different cross-sections.

The goal of the experimental tests was to determine the thermal stress level of the contact terminal area between the impedance bond terminals and connectors of the connection ropes through the condition-monitoring device, and with an infrared device to validate the measurements. The experiments were performed in laboratory conditions.

The tests were carried out using the installation shown in Figure 6, which contains the following elements: the main switch $\mathrm{K}$, which supplies with low voltage the power sources composed of an autotransformer $(200 \mathrm{kVA})$ and a power transformer $(250 \mathrm{kVA})$, the non-metallic casing impedance bond (250 A), the connecting conductors between the impedance bond and the railway tracks (steel and copper connection ropes), two railway tracks with a length of one meter, the monitoring device with two current transformers (CT1 and CT2), and NTC temperature sensors (TS) for monitoring the 
temperature of the terminals of impedance bond connections (A1-M-A2, Figure 2) and for the ambient temperature (AM).

The object, which is under testing, is the impedance bond in the non-metallic casing that is mounted in the electric traction return circuit, starting before 2014, in Romania. They appeared as a result of the advantages over the classic impedance bond in the sense that they can be mounted between the railway tracks, no longer require cooling oil (impregnated with resin), and have small weight and dimensions.

The experimental setup was realized in the laboratory and aimed to present the real situation encountered in the field. The experimental tests were performed by connecting the impedance bond terminals to the railway tracks in some situation that could occur in exploitation, based on statistics and historical database. Thus, the following cases were selected:

- a healthy condition-connecting the railway tracks with the impedance bond through a copper cable with a section of $50 \mathrm{~mm}^{2}$ with PVC insulation;

- a healthy condition - connecting the railway tracks with the impedance bond through two steel cable with a section of $78 \mathrm{~mm}^{2}$ with PVC insulation;

- a faulty condition-connecting the railway tracks with the impedance bond through one steel cable with a section of $78 \mathrm{~mm}^{2}$ with PVC insulation. This fault may occur when a steel cable between the impedance bond terminals and the railway track are interrupted;

- a faulty condition-insufficient tightening of the connection terminals. The appearance of this fault in the return circuit is explained by loosening the tightening of screw nuts, oxidation, rust, etc.

The impedance bond tests consisted of passing different currents through the experimental installation. Those currents are similarly with the return circuit ones and can produce thermal stresses of the impedance bonds (100 A, $150 \mathrm{~A}$, and $200 \mathrm{~A}$ ). The current is passing through each railway track, connecting cable, and the semi winding of the impedance bond. Data associated with the currents was acquired by the condition-monitoring device, respectively, the temperatures to evaluate the thermal stresses in the contact area. The ambient temperature at the time of the experiments was about $20^{\circ} \mathrm{C}$.

Moreover, before each test at the specified current values, the contact resistance measurements with a dedicated apparatus, Micro Ohmmeter RMO 500 A, was performed. These measurements are essential because, at different values of contact resistances, the thermal stress is influenced. The values of the contact resistances resulting from the measurements made are presented in Table 3.

Table 3. Contact resistance values from the impedance bond terminal.

\begin{tabular}{ccccc}
\hline \multirow{2}{*}{ Case } & \multirow{2}{*}{$\begin{array}{c}\text { Connecting Mode between Impedance Bond } \\
\text { Terminal and Railway Track }\end{array}$} & \multicolumn{3}{c}{$\mathbf{R}_{\mathbf{c}}(\mu \Omega)$} \\
\cline { 3 - 5 } & & With a copper connecting cable & $\mathbf{1 5 0 ~ A}$ & $\mathbf{2 0 0 ~ A}$ \\
\hline $\mathbf{1}$ & With two steel connecting cables & 27.1 & 27.4 & 27.3 \\
\hline $\mathbf{2}$ & With a steel connecting cable & 54.9 & 53.8 & 46.3 \\
\hline $\mathbf{3}$ & & &
\end{tabular}

4.2. First Case-Healthy Condition When the Connection of the Railway Tracks with the Impedance Bond Is Made through a Copper Cable with a Section of $50 \mathrm{~mm}^{2}$ with PVC Insulation

In the first case, what was analyzed was the situation when the connection between the impedance bond terminal and railway track was realized, with copper rope with a section of $50 \mathrm{~mm}^{2}$. Figure 7 presents the temperature variation in the contact area, when it is passing with different currents. Thus, after $3600 \mathrm{~s}$ from the passage of currents (above the temperature values) were obtained: at $100 \mathrm{~A}$, the temperature was $32.3^{\circ} \mathrm{C}$; at $150 \mathrm{~A}$, the temperature was $39.3^{\circ} \mathrm{C}$, respectively, for $200 \mathrm{~A}$, the temperature was $48.6^{\circ} \mathrm{C}$. The different evolutions of the temperatures are mainly due to the different values of the currents because of the contact resistances having close values. 


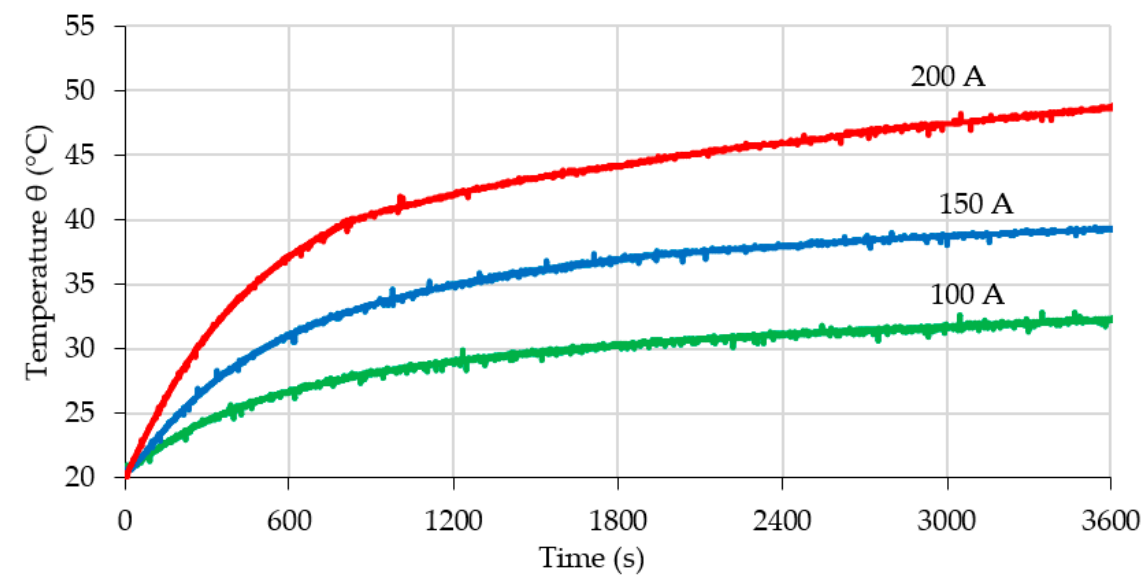

Figure 7. Temperature variation from the contact area by impedance bond and one copper conductor at different currents $(100 \mathrm{~A}, 150 \mathrm{~A}, 200 \mathrm{~A})$.

4.3. Second Case-Healthy Condition When the Connection of the Railway Tracks with the Impedance Bond Is Made through Two Steel Cables with a Section of $78 \mathrm{~mm}^{2}$ with PVC Insulation

In addition, the case of the connection between an impedance bond terminal and railway track with two steel ropes was analyzed. The values of the contact resistances to the contact area are given in Table 3. Figure 8 shows the time evolution of the temperature after the different currents passing the contact area. Thus, the following temperature values were obtained: for $100 \mathrm{~A}$, a $34.8^{\circ} \mathrm{C}$ value; for $150 \mathrm{~A}$, a $46.1^{\circ} \mathrm{C}$ temperature value; and for $200 \mathrm{~A}$, a temperature value of $61.2^{\circ} \mathrm{C}$.

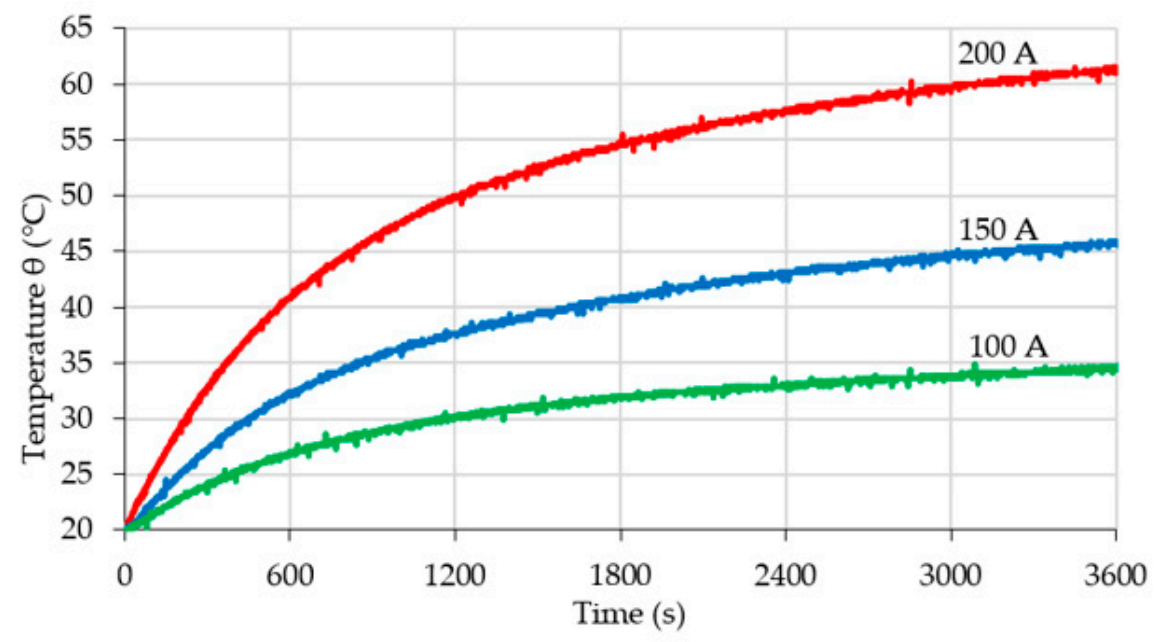

Figure 8. Temperature variation from the contact area by impedance bond and two steel conductors at different currents (100 A, 150 A, 200 A).

Analyzing the contact area temperature, corresponding the first case (at $3600 \mathrm{~s}$ and $100 \mathrm{~A}$ currents passed) with the second case, it can be observed that $32.3^{\circ} \mathrm{C}$ value is closed with $34.8^{\circ} \mathrm{C}$ value, the difference being smallest than $2.5^{\circ} \mathrm{C}$. Although the contact resistance in the first case is higher than in the second case, the overheating is closed; this is due to the increase of the heat transfer surface in the second case.

Since the thermal stresses in the case of contact with the copper rope are smaller, these connections should be made from this material. However, for economic reasons (not only robberies, vandalism), in operation, the connections with two steel cables are used. 
4.4. Third Case-Faulty Condition When Connecting the Railway Tracks with the Impedance Bond Is Made through One Steel Cable with a Section of $78 \mathrm{~mm}^{2}$ with PVC Insulation

This fault may occur when a steel cable between the impedance bond terminal and the railway track is broken because of overheating, railway accidents, etc.

Figure 9 shows the temperature variation in the terminal contact area of the impedance bond when it is connected by a steel rope to the railway track, at the same values of the currents as the other cases. The temperature reaches to $52.5^{\circ} \mathrm{C}$, for a current of $100 \mathrm{~A}, 78.5^{\circ} \mathrm{C}$ for $150 \mathrm{~A}$, and $124.4^{\circ} \mathrm{C}$ for $200 \mathrm{~A}$. Moreover, the temperature in the terminal contact area has different evolutions due to the current values; the contact resistances, having almost the same values, do not influence the measurements.

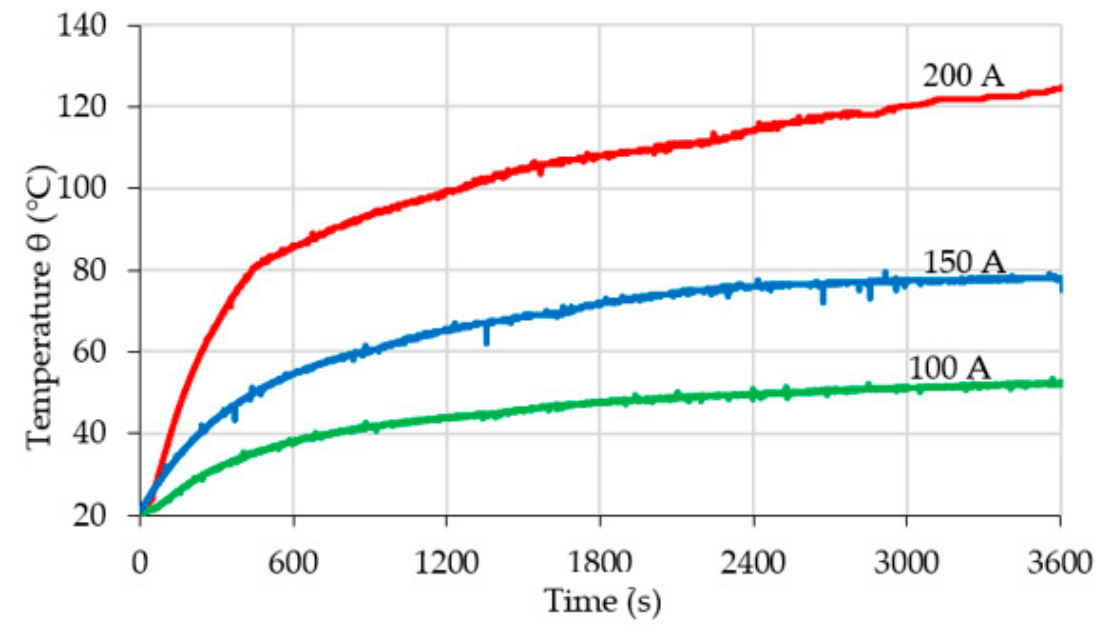

Figure 9. Temperature variation from the contact area by impedance bond and one steel conductor at different currents (100 A, 150 A, 200 A).

By comparing the obtained results with the first case at the same transited current, the temperature in the contact area is higher (for example, at $100 \mathrm{~A}$, it has $52.5^{\circ} \mathrm{C}>32.3^{\circ} \mathrm{C}$ ). This big difference, $20.2^{\circ} \mathrm{C}$, is because the resistivity of the steel is higher than the copper resistivity, which will cause higher Joule losses on the steel rope.

In addition, Figure 9 shows that, with the increase of the current over a certain value, the temperatures will exceed the allowable limits given by the impedance bonds manufacturer $\left(105^{\circ} \mathrm{C}\right.$ on the terminal contact). At $200 \mathrm{~A}$, with a single connecting rope, the values of the temperatures in the contact area exceed the allowable value, after approximately $1545 \mathrm{~s}$. This fact can lead to thermal overloading of the impedance bond semi-windings from the ends of the circulation sector on which the abnormal situation appeared, respectively, to the blocking of the control circuit in that circulation sector. In this case, a maintenance activity to complete the connection between impedance bond and railway tracks with another steel connection ropes are necessary.

Moreover, a thermographic image was performed, when the connection of the railway tracks with the impedance bond was made through a copper cable (healthy condition) and the connection with one steel cable (faulty condition). The thermal investigation was made with an infrared thermographic investigation device, FLIR T650sc, for validation of the contact thermal stresses level between the terminal of the impedance bond and the connection cable. The thermographic camera resolution is $640 \times 480$ pixels and accuracy of $\pm 1{ }^{\circ} \mathrm{C}$ or $\pm 1 \%$ for the temperature range $-40{ }^{\circ} \mathrm{C}$ to $160{ }^{\circ} \mathrm{C}$.

Before viewing the infrared thermal image, the camera was configured according to the laboratory conditions. The values of the adjustment parameters for obtaining the thermographic image were the following:

- ambient temperature: $20^{\circ} \mathrm{C}$;

- the emissivity index: this parameter has been set to the value of 0.9 ; 
- reflected temperature: set equal to ambient temperature, $20^{\circ} \mathrm{C}$;

- relative humidity of the air: the value measured in the laboratory at the time of the experiment was $55 \%$;

- the distance from the camera lens to the investigated connection was $1.5 \mathrm{~m}$;

- the temperature range was selected from -30 to $160^{\circ} \mathrm{C}$.

The obtained thermographic image was processed using FLIR Tools software, to identify the temperatures recorded on each contact area and connecting conductor. Thus, the surface points Sp1, $\mathrm{Sp} 2$ are shown the temperatures recorded for the copper conductor when current flow through to circuit at its value 100A, Figure 10. Moreover, the Sp3, Sp4 points give the temperature values of the steel conductor.
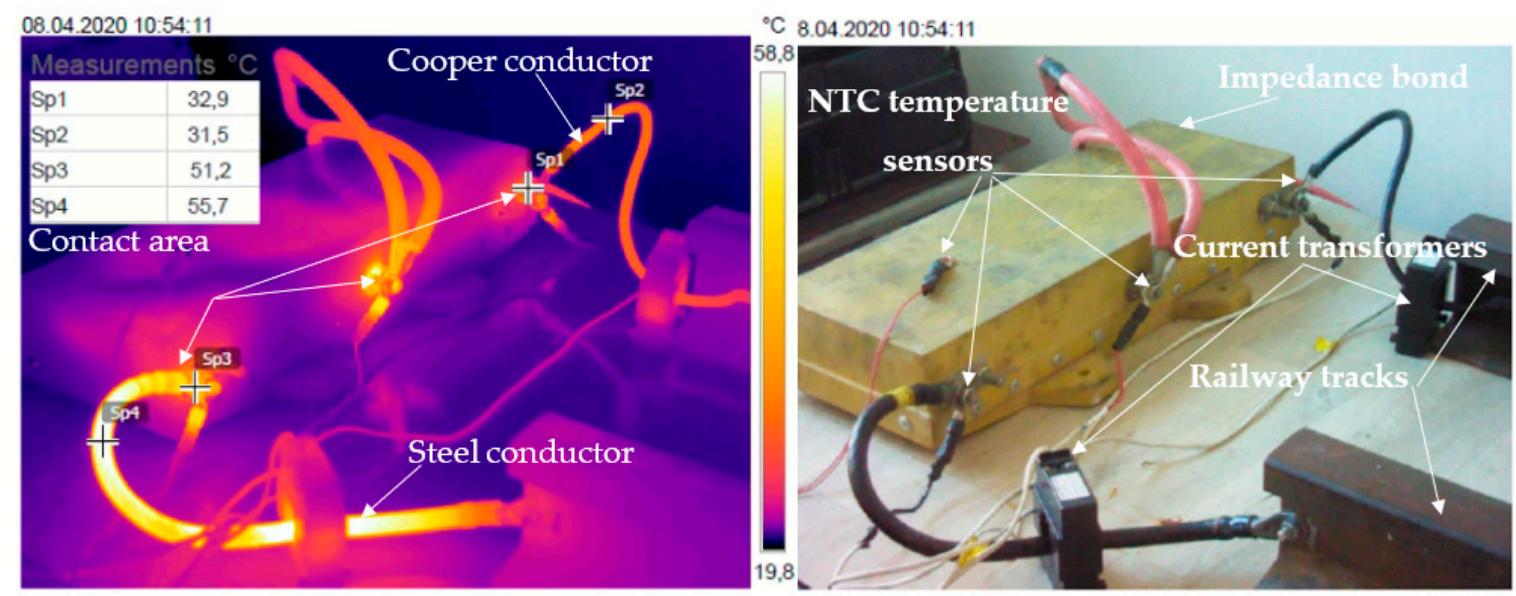

Figure 10. Thermographic image at a test current of $100 \mathrm{~A}$.

The temperature obtained with the infrared device is close to that acquired with the experimental device for condition monitoring of the impedance bond. Thus, the temperature values on the contact area between the connecting ropes and impedance bond terminal are for the copper connection, $32.9{ }^{\circ} \mathrm{C}$, as against $32.3^{\circ} \mathrm{C}$ obtained with the monitoring device. To the steel connection, the thermographic temperature was $51.2^{\circ} \mathrm{C}$, as against $52.5^{\circ} \mathrm{C}$ achieved with the monitoring device.

Moreover, it can be observed that the contact area in the case with the steel cable is supplementary heated by the steel connecting rope, which has a higher temperature than the contact area. The steel connection rope is a thermal source for the contact area at the impedance bond terminal.

\subsection{Fourth Case-Faulty Condition with Insufficient Tightening (High Contact Resistance) of the Connection Terminals}

In the return circuit, in addition to the main elements, such as railway tracks, impedance bonds, connecting conductors between railway tracks, and impedance bonds, return feeders represent the electrical contacts between them. The electrical contacts introduce, in the traction current path, an additional electrical resistance. The appearance of the contact resistances in the return circuit is explained by covering the contact parts with disruptive films (oxidation, rust, etc.) and by changing the contact areas (loosening the tightening of screw nuts) between them.

Moreover, to highlight the influence of the contact resistance measurements, these values have been modified through loosening the tightening of screw nuts.

The tightening torque of the screw nuts, which, connecting the impedance bond terminal and the connecting conductor, was according to the connection standards, and having a value of $30 \mathrm{Nm}$, measured with a torque wrench. At this value of tightening torque, the contact resistance was $54.9 \mu \Omega$. After losing the screw nuts, the value of tightening torque was $8 \mathrm{Nm}$, which corresponds with a $166.7 \mu \Omega$ contact resistance value measured with the RMO 500 micro ohmmeter. 
This experiment was done when the connection between the impedance bond and the railway track was connected by one steel conductor (the worst case possible). Thus, in Figure 11, it shows the temperature evolution in the contact area, for a current of $100 \mathrm{~A}$ and a duration of $3600 \mathrm{~s}$, at two different values of the contact resistances $(54.9 \mu \Omega$ and $166.7 \mu \Omega)$ between the impedance bond terminal and connection cable. The tests were performed in the same configuration as in the third case. It can observe that there is a significant increase in temperature $\left(95.8^{\circ} \mathrm{C}>52.5^{\circ} \mathrm{C}\right)$, due to the change of the contact resistance leading to a pronounced thermal stress.

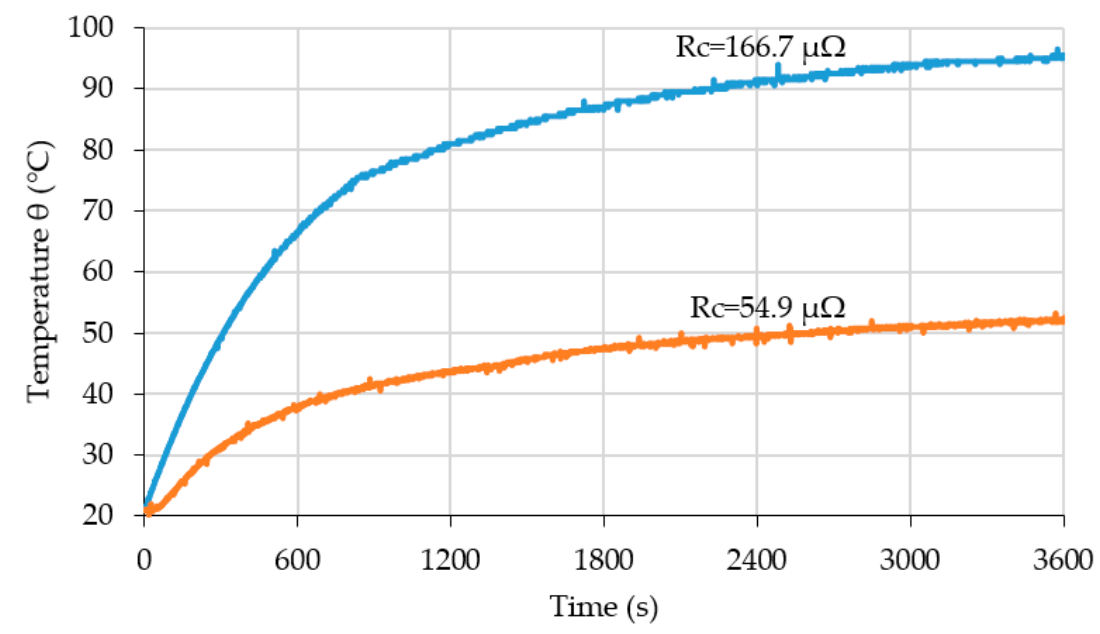

Figure 11. Temperature variation from the contact area by different contact resistances.

Moreover, given the previous case, when the current increases over a certain value, the temperatures will reach the allowable limits. This will lead to contact overheating and burning. In such conditions, the monitoring device will launch an alarm in order to require a maintenance activity. To immediately repair or replace the damaged contact, the device indicates the place where the impedance bond is mounted in the field.

In conclusion, the thermal stress in the contact area is given by the following: the current, which passes the return circuit, the material parameters, the contact resistance, the material resistivity, is further heated by the connecting ropes, in some cases, which become a thermal source for the contact area.

\section{Conclusions}

The necessity of monitoring the impedance bonds increases due to their importance in ensuring the traction current return to the power supply, respectively, to the control and signaling of the railway vehicles to achieve the safety of railway traffic. A fault of the impedance bond will block the signaling circuit, which will lead to the interruption of the power supply system from electric traction, including the train movement in the respective sector.

The monitoring and diagnosis of the impedance bonds will lead to the reduction of delays in the circulation of trains, delays caused by the failure of the signaling installations.

Limiting the adverse effects of such an event, respectively, removing as much as possible of the occurrence of abnormal situations, can be achieved by knowing the essential parameters of the impedance bond that influence its operation.

In this context, a device for monitoring and diagnosing of impedance bonds was designed and realized. The hardware architecture of the device was designed for working conditions specific to the electric traction, being made a compact and robust structure, suitable for insertion in housing that can be mounted on the omega rail, the rail commonly used in switchboards.

The novelty character of the device is: 
- knowing the currents through the two primary coils of the impedance bond, the temperatures on the contact terminals, on the metallic or non-metallic housing of the coil, and the ambient temperatures;

- impedance bond diagnosis (a higher temperature in the contact areas, a higher of the current imbalance through the two running rails, the interruption of the connecting conductors between the impedance bond terminals and railway track, etc.);

- real-time knowledge of the technical condition of the impedance bond by analyzing the acquired data and comparing it with previous records;

- the device has high flexibility, both at the hardware structure (the possibilities of extending of inputs number, respectively, possibly extending the storage capacity), and also to the software (upgrading the firmware at the device location).

The monitoring and diagnosis of impedance must allow good knowledge of the technical condition of the impedance bonds to retain their behavior in the most varied situations, and it compared with a database of others of the same equipment type, but exposed under similar conditions.

The thermal stresses of the return circuit from the electric railway traction are produced by the electrocaloric effect of the current flowing through them. Thus, an experimental test setup to determine the thermal stress level of the contact terminal area between the impedance bond terminals and connectors (of the connection ropes), through a condition monitoring device, and with an infrared device for validating the measurements, was realized.

The experimental tests performed in the laboratory on the impedance bond tested with various modes of connection to the railway tracks, showed, on the one hand, a good functioning of the monitoring device, thus fulfilling the purpose for which it was designed and realized. On the other hand, the thermal stresses of the monitored impedance bonds were correctly highlighted. Those aspects are shown by comparing the values monitored with the experimental device and with the infrared thermographic investigation device.

Based on the present achievements, future research will focus on developing a software application in LabVIEW for an easy interface with the operator.

Finally, for future work, there will be a desire to realize the modeling and simulation of the ensemble with finite element analysis software, such as COMSOL Multiphysics.

\section{Patents}

Adam M., Munteanu A., Pancu C.M., Andrusca M., "Method and apparatus for monitoring and diagnosis of impedance bond", Request patent nr. a 00233, 2017, Romania.

Author Contributions: Conceptualization, M.A. (Mihai Andrusca), M.A. (Maricel Adam), and A.D.; methodology, M.A. (Mihai Andrusca), M.A. (Maricel Adam), and A.D.; software, M.A. (Mihai Andrusca), M.A. (Maricel Adam), R.S., and O.P.; validation, M.A. (Mihai Andrusca), M.A. (Maricel Adam), A.D., and E.L.; formal analysis, M.A. (Mihai Andrusca), M.A. (Maricel Adam), and A.D.; investigation, M.A. (Mihai Andrusca), M.A. (Maricel Adam), and A.D.; resources, M.A. (Mihai Andrusca), M.A. (Maricel Adam), A.D., R.S., and O.P.; data curation, M.A. (Mihai Andrusca), M.A., A.D., and O.P.; writing-original draft preparation, M.A. (Mihai Andrusca) and M.A. (Maricel Adam); writing-review and editing, M.A. (Maricel Adam), A.D., E.L., R.S., and O.P. All authors have read and agreed to the published version of the manuscript.

Funding: This research received no external funding.

Acknowledgments: This paper was realized with the support of the project "Institutional Development of TUIASI through Increasing the Visibility and Research Performance of TUIASI-COMPETE", financed by Contract no. 9PFE/2018, project funded by Romanian Government.

Conflicts of Interest: The authors declare no conflict of interest.

\section{References}

1. Tsunashima, H. Condition monitoring of railway tracks from car-body vibration using a machine learning technique. Appl. Sci. 2019, 9, 2734. [CrossRef] 
2. Garramiola, F.; Poza, J.; Olmo, J.; Madina, P.; Almandoz, G. Integral sensor fault detection and isolation for railway traction drive. Sensors 2018, 18, 1543. [CrossRef] [PubMed]

3. Berlin, E.; Laerhoven Van, K. Sensor networks for railway monitoring: Detecting trains from their distributed vibration footprints. In Proceedings of the 2013 IEEE International Conference on Distributed Computing in Sensor Systems, Cambridge, MA, USA, 20-23 May 2013.

4. Chen, J.; Roberts, C.; Weston, P. Fault detection and diagnosis for railway track circuits using neuro-fuzzy systems. Control Eng. Pract. 2008, 16, 585-596. [CrossRef]

5. Zhao, L.H.; Wu, J.P.; Ran, Y.K. Fault diagnosis for track circuit using AOK-TFRs and AGA. Control Eng. Pract. 2012, 20, 1270-1280.

6. Hodge, V.; O'Keefe, S.; Weeks, M.; Moulds, A. Wireless sensor networks for condition monitoring in the railway industry: A survey. IEEE Trans. Intell. Transp. Syst. 2015, 16, 1088-1106. [CrossRef]

7. Ngamkhanong, C.; Kaewunruen, S.; Afonso Costa, B. State-of-the-art review of railway track resilience monitoring. Infrastructures 2018, 3, 3. [CrossRef]

8. Bernal, E.; Spiryagin, M.; Cole, C. Onboard condition monitoring sensors, systems and techniques for freight railway vehicles: A review. IEEE Sens. J. 2019, 19, 4-24. [CrossRef]

9. Gardea, C.; Dumitru, D.; Ciobotar, A.; Niculescu, O. Impedance Bond. Romania Patent RO 123523 B1, 29 May 2013.

10. Sando, D.; Lakes, L. Double Impedance Bond. U.S. Patent US 8,333,350 B2, 18 December 2012.

11. Munteanu, A.; Adam, M.; Andrusca, M.; Dragomir, A.; Boghiu, E. Aspects regarding the monitoring of electrical equipment from electric traction. In Proceedings of the 10th EPE 2018, Iaşi, Romania, 18-19 October 2018.

12. Adam, M.; Munteanu, A.; Pancu, C.M.; Andrusca, M. Method and Apparatus for Monitoring and Diagnosis of Impedance Bond. Romania Patent Request nr. a 00233, 29 September 2017.

13. Bruin, T.; Verbert, K.; Robert Babuska, R. Railway track circuit fault diagnosis using recurrent neural networks. IEEE Trans. Neural Netw. Learn. Syst. 2016, 28, 523-533. [CrossRef]

14. Yuan, L.; Yang, Y.; Hernández, A.; Shi, L. Feature extraction for track section status classification based on UGW signals. Sensors 2018, 18, 1225. [CrossRef]

15. Polivka, A.L.; West, P.; Malone, J.; Smith, B.E.; Renfrow, S.M. System and Method for Detecting Broken Rail and Occupied Track from a Railway Vehicle. U.S. Patent US 9,162,691 B2, 20 October 2015.

16. Turabimana, P.; Nkundineza, C. Development of an onboard measurement system for railway vehicle wheel flange wear. Sensors 2020, 20, 303. [CrossRef]

17. Tsunashima, H.; Kojima, T.; Marumo, Y.; Matsumoto, H.; Mizuma, T. Condition monitoring of railway track using in-service vehicle. In Proceedings of the 4th IET International Conference of Railway Condition Monitoring, Derby, UK, 18-20 June 2008.

18. Tsunashima, H.; Naganuma, Y.; Matsumoto, A.; Mizuma, T.; Mori, H. Japanese Railway Condition Monitoring of Tracks using in-Service Vehicle. In Proceedings of the 5th IET Conference on Railway Condition Monitoring and Non-Destructive Testing (RCM 2011), Derby, UK, 29-30 November 2011.

19. Tsunashima, H.; Mori, H.; Yanagisawa, K.; Ogino, M.; Asano, A. Condition monitoring of railway tracks using compact size on-board monitoring device. In Proceedings of the 6th IET Conference on Railway Condition Monitoring (RCM), Birmingham, UK, 17-18 September 2014.

20. Chen, J.; Díaz, M.; Rubio, B.; Troya, J.M. RAISE: Railway Infrastructure health monitoring using wireless sensor networks. Sens. Syst. Softw. 2013, 122, 143-157.

21. Bennett, P.J.; Soga, K.; Wassell, I.; Fidler, P.; Abe, K.; Kobayashi, Y.; Vanicek, M. Wireless sensor networks for underground railway Applications: Case studies in Prague and London. Smart Struct. Syst. 2010, 6, 619-639. [CrossRef]

22. Flammini, F.; Gaglione, A.; Ottello, F.; Pappalardo, A.; Pragliola, C.; Tedesco, A. Towards wireless sensor networks for railway infrastructure monitoring. In Proceedings of the Electrical Systems for Aircraft, Railway and Ship Propulsion, Bologna, Italy, 19-21 October 2010; pp. 1-6.

23. Bin, S.; Sun, G. Optimal energy resources allocation method of wireless sensor networks for intelligent railway systems. Sensors 2020, 20, 482. [CrossRef] [PubMed]

24. Gao, M.; Wang, P.; Wang, Y.; Yao, L. Self-Powered ZigBee Wireless sensor nodes for railway condition monitoring. IEEE Trans. Intell. Transp. Syst. 2018, 19, 900-909. [CrossRef] 
25. Gao, M.; Li, Y.; Lu, J.; Wang, Y.; Wang, P.; Wang, L. Condition monitoring of urban rail transit by local energy harvesting. Intern. J. Distrib. Sens. Netw. 2018, 14, 1550147718814469. [CrossRef]

26. Buggy, S.; James, S.W.; Carroll, R.; Jaiswal, J.; Staines, S.; Tatam, R.P. Intelligent infrastructure for rail and tramways using Optical fibre sensors. In Proceedings of the IET Railway Young Professionals, Best Paper Competition, London, UK, 16-18 November 2011.

27. Garramiola, F.; Poza, J.; Olmo, J.; Madina, P.; Almandoz, G. DC-link voltage and catenary current sensors fault reconstruction for railway traction drives. Sensors 2018, 18, 1998. [CrossRef]

28. Mariscotti, A.; Pozzobon, P. Determination of the electrical parameters of railway traction lines: Calculation, measurement and reference data. IEEE Trans. Power Deliv. 2004, 19, 1538-1546. [CrossRef]

29. Mariscotti, A. Direct measurement of power quality over railway networks with results of a $16.7 \mathrm{~Hz}$ network. IEEE Trans. Instrum. Meas. 2011, 60, 1604-1612. [CrossRef]

30. Dolara, A.; Gualdoni, M.; Leva, S. Impact of high-voltage primary supply lines in the $2 \times 25 \mathrm{kV}, 50 \mathrm{~Hz}$ railway system on the equivalent impedance at pantograph terminals. IEEE Trans. Power Deliv. 2012, 27, 164-175. [CrossRef]

31. Chiriac, G.; Nituca, C.; Cardasim, M. Failures analysis in the 25 kV/50 Hz railway substations. In Proceedings of the 2017 International Conference on Electromechanical and Power Systems (SIELMEN), Iasi, Romania, 11-13 October 2017.

32. Onea, R. Construction, Operation and Maintenance of Fixed Railway Traction Installations; Publisher ASAB: Bucharest, Romania, 2004.

33. Mariscotti, A. Distribution of the traction return current in AC and DC electric railways systems. IEEE Trans. Instr. Meas. 2003, 18, 1422-1432. [CrossRef]

34. Munteanu, A.; Adam, M.; Andrusca, M.; Dragomir, A.; Boghiu, E. Possibility to monitoring and diagnosis the joint coils from electric traction. In Proceedings of the 10th EPE 2018, Iaşi, România, 18-19 October 2018.

35. Filograno, M.L.; Guillén, P.C.; Rodríguez-Barrios, A.; Martín-López, S.; Rodríguez-Plaza, M.; Andrés-Alguacil, Á.; González-Herráez, M. Real-time monitoring of railway traffic using Fiber Bragg grating sensors. IEEE Sens. J. 2012, 12, 85-92. [CrossRef]

(C) 2020 by the authors. Licensee MDPI, Basel, Switzerland. This article is an open access article distributed under the terms and conditions of the Creative Commons Attribution (CC BY) license (http://creativecommons.org/licenses/by/4.0/). 